\title{
Facile Synthesis of Colloidal CuO Nanocrystals for Light-Harvesting Applications
}

\author{
Yee-Fun Lim, Joshua J. Choi, and Tobias Hanrath \\ School of Chemical and Biomolecular Engineering, Cornell University, Ithaca, NY 14853-1501, USA \\ Correspondence should be addressed to Tobias Hanrath, th358@cornell.edu
}

Received 25 May 2011; Accepted 14 July 2011

Academic Editor: Fan Zhang

Copyright () 2012 Yee-Fun Lim et al. This is an open access article distributed under the Creative Commons Attribution License, which permits unrestricted use, distribution, and reproduction in any medium, provided the original work is properly cited.

$\mathrm{CuO}$ is an earth-abundant, nontoxic, and low band-gap material; hence it is an attractive candidate for application in solar cells. In this paper, a synthesis of $\mathrm{CuO}$ nanocrystals by a facile alcohothermal route is reported. The nanocrystals are dispersible in a solvent mixture of methanol and chloroform, thus enabling the processing of $\mathrm{CuO}$ by solution. A bilayer solar cell comprising of $\mathrm{CuO}$ nanocrystals and phenyl-C61-butyric acid methyl ester (PCBM) achieved a power conversion efficiency of $0.04 \%$, indicating the potential of this material for light-harvesting applications.

\section{Introduction}

Solution-processable solar cell technologies can enable the realization of low-cost and high-throughput photovoltaic production [1]. While much work has previously focused on organic semiconductors [1], colloidal inorganic semiconductor nanocrystals (NCs) are starting to attract attention for photovoltaic applications [2]. NCs have the advantages of being solution-processable, capable of absorbing a large fraction of the solar spectrum, and tunable band-gap due to quantum-confinement effects [2]. While early NC solar cell work was based on CdSe [3] and CdTe [4], impressive results have been achieved with $\mathrm{CuInSe}_{2}$ [5], PbSe [6-10], and $\mathrm{PbS}$ [11-15] NCs in recent years. In particular, Sargent and coworkers have reported a $\mathrm{PbS} \mathrm{NC} / \mathrm{TiO}_{2}$ bi-layer solar cell with a power conversion efficiency (PCE) as high as $5.1 \%$ [15].

The above-mentioned materials may be good test-beds for studies of NCs as photovoltaic materials but may not be feasible candidates for wide-spread deployment due to toxicity and availability- $\mathrm{Cd}$ and $\mathrm{Pb}$ are toxic heavy metals, while In and Te are among the least abundant elements in the Earth's crust [16]. It is thus desirable to explore other alternative solar cell materials. Copper- and iron-based semiconductors have emerged as attractive materials from an analysis by Wadia et al. based on abundance and cost [17].
For instance, $\mathrm{Wu}$ et al. [18] recently reported a $\mathrm{Cu}_{2} \mathrm{~S} \mathrm{NC}$ based solar cell with a promising PCE of 1.6\%. Copper (I) oxide $\left(\mathrm{Cu}_{2} \mathrm{O}\right)$ and copper (II) oxide $(\mathrm{CuO})$ are also attractive candidates for light-harvesting applications due to their band gap energies of $1.4 \mathrm{eV}$ (indirect) for $\mathrm{CuO}$ [19] and $2.0 \mathrm{eV}$ (direct) for $\mathrm{Cu}_{2} \mathrm{O}[20]$ that are quite close to the ideal bandgap for a single junction photovoltaic cell estimated from detailed balance [21]. $\mathrm{Cu}_{2} \mathrm{O}$ has been investigated as a solar cell material for several decades [22], with recent reports of PCE up to $2.0 \%$ [23-25]. $\mathrm{CuO}$ has been employed in photo-electrochemical cells $[26,27]$ and as a cathode for dyesensitized solar cells [28]. The use of $\mathrm{CuO}$ as the active layer in solid state solar cells has, to the best of our knowledge, not yet been investigated, and is the focus of this work. From a detailed balance analysis, $\mathrm{CuO}$ with a band gap of $1.4 \mathrm{eV}$ can reach an ultimate solar cell efficiency of almost $30 \%$, significantly higher than the $20 \%$ limit for $\mathrm{Cu}_{2} \mathrm{O}(2.0 \mathrm{eV}$ band gap) [21].

Copper oxide NC syntheses via various routes have been reported in the literature [29-44]. Relatively few of these reports, however, discuss the dispersibility of copper oxide NCs in common solvents [41-44], which is critical for solution-based processing of $\mathrm{NC}$ thin film absorber layers. In particular, Yuhas and Yang [43] and Hung et al. [44] reported solar cells based on films spin-coated from $\mathrm{Cu}_{2} \mathrm{O}$ NC solutions, with PCE from $0.05 \%$ to $0.14 \%$. In this 
paper, the synthesis of colloidal $\mathrm{CuO}$ NCs by a facile alcohothermal method is reported. The NCs are characterized by transmission electron microscopy (TEM), X-ray diffraction (XRD), Fourier transform infrared spectroscopy (FTIR), and UV-visible absorption spectroscopy. Finally, as a proof of concept, a bilayer solar cell-based on $\mathrm{CuO}$ and phenyl- $\mathrm{C}_{61^{-}}$ butyric acid methyl ester (PCBM) is demonstrated.

\section{Experimental}

2.1. Synthesis of $\mathrm{CuONCs.} 0.29 \mathrm{~g}$ of copper (II) acetate (Sigma Aldrich) was added to $30 \mathrm{~mL}$ of reagent alcohol (Sigma Aldrich) under vigorous stirring. $1 \mathrm{~mL}$ of deionized (DI) water was added, and the mixture was heated to $75^{\circ} \mathrm{C}$. In a separate container, $1.3 \mathrm{~mL}$ of $25 \%$ tetramethylammonium hydroxide (TMAH) in methanol (Sigma Aldrich) was added to $10 \mathrm{~mL}$ of reagent alcohol. After 15 minutes of stirring, when the copper acetate has fully dissolved, the TMAH solution was gradually added over 5 minutes in regular intervals. The reaction was allowed to proceed at $75^{\circ} \mathrm{C}$ for 60 minutes, and the resultant product was collected by precipitation with hexane and then centrifuging at $3750 \mathrm{rpm}$ for 5 minutes.

2.2. NC Characterization. TEM samples were prepared by drop-casting very dilute NC suspensions in methanol onto carbon grids (Electron Microscopy Sciences), and images were taken using an FEI T12 Spirit TEM. X-ray diffraction was performed on a Bruker General Area Detector Diffraction System (GADDS). A Thermo Scientific Nicolet iS10 FTIR spectrometer was used to perform FTIR spectroscopy on NC samples drop-casted from methanol. These NCs have been washed and centrifuged three times with reagent alcohol to get rid of unreacted precursors. UV-visible absorption spectroscopy was performed using a Shimadzu UV-3101PC UV/Vis/Near-IR Spectrophotometer. All film thickness measurements were done using a Tencor P10 Profilometer.

2.3. Solar Cell Fabrication and Testing. Solar cells were fabricated on prepatterned indium tin oxide (ITO) coated glass substrates (Kintec, Hong Kong), which were cleaned by sonication in a mild detergent, rinsed in deionized water, dried in a nitrogen stream, and treated with a 10-minute UV-ozone exposure. $\mathrm{CuO}$ NCs were dispersed in a solvent mixture of $2: 1$ chloroform and methanol at a concentration of $\sim 10 \mathrm{mg} \mathrm{mL}^{-1}$, and then spin-coated on top of the ITO at $2000 \mathrm{rpm}$ to give a film $\sim 40 \mathrm{~nm}$ thick. A cell with a thicker $\mathrm{CuO}$ layer $(\sim 70 \mathrm{~nm})$ was also fabricated by performing the spin-coating step 3 times. This is possible because the underlying layer is not completely dissolved during the spincoating of subsequent layers. PCBM solution $\left(20 \mathrm{mg} \mathrm{mL}^{-1}\right.$ in chloroform) was then spin-coated on top of the $\mathrm{CuO}$ at $2000 \mathrm{rpm}$ to give a film $\sim 120 \mathrm{~nm}$ thick. Finally, $4 \AA$ of $\mathrm{CsF}$ and $400 \AA$ of $\mathrm{Al}$ were thermally evaporated under high vacuum $\left(\sim 10^{-6}\right.$ Torr $)$ to form the cathode for the devices. A shadow mask was used in the evaporation to define a device-active area of $3 \mathrm{~mm}^{2}$. Control PCBM-only solar cells (without $\mathrm{CuO}$ ) were also fabricated.
Device current-voltage curves were obtained with a Keithley 236 source-measurement-unit (SMU) in the dark and as well as under AM $1.5100 \mathrm{~mW} \mathrm{~cm}^{-2}$ illumination from a Solar Light 16S-002 solar simulator. Light output power was calibrated using a Newport 818P-010-12 thermopile high power detector, which has a flat response over a broad spectral range. EQE measurements were performed using a Newport $1000 \mathrm{~W}$ xenon lamp coupled to an Oriel Cornerstone $2601 / 4 \mathrm{~m}$ monochromator as the light source, a Keithley 236 SMU to measure short circuit current, and a Newport 918D-UV3-OD3 low power detector to monitor the light intensity.

\section{Results and Discussion}

The CuONC synthesis is modified from a previously reported method for the synthesis of soluble zinc oxide NCs $[9,45]$. Copper (II) acetate, $\mathrm{Cu}(\mathrm{OAc})_{2}$, was dissolved in reagent alcohol and then reacted with tetramethylammonium hydroxide (TMAH) to form copper (II) hydroxide. $\mathrm{CuO}$ was then formed through heating:

$$
\begin{gathered}
\mathrm{Cu}^{2+}+2(\mathrm{OH})^{-} \longrightarrow \mathrm{Cu}(\mathrm{OH})_{2} \\
\mathrm{Cu}(\mathrm{OH})_{2} \longrightarrow \mathrm{CuO}+\mathrm{H}_{2} \mathrm{O} \quad\left(\mathrm{T}=75^{\circ} \mathrm{C}\right)
\end{gathered}
$$

Figure 1(a) shows TEM image of $\mathrm{CuO}$ NCs, in which it can be seen that they have a rather large size distribution of around $4-5 \mathrm{~nm}$. The relatively broad size distribution of the $\mathrm{CuONCs}$ is likely the result of the nucleation and growth dynamics of the reaction. Unlike the "hot-injection" synthesis [46], the simplified alcohothermal method lacks a single well-defined nucleation event leading to broader NC diameter distributions. X-ray diffractograms (Figure 1(b)) of the NCs are consistent with the literature values for $\mathrm{CuO}$ (JPCD no. 05-0661). It was observed that the addition of a small amount of deionized (DI) water (3\% by volume) during the $\mathrm{CuO}$ synthesis produced NCs with more welldefined and narrower XRD peaks as compared to NCs synthesized without water. In previously reported syntheses of $\mathrm{ZnO}$ nanoparticles with zinc acetate in alcohol $[47,48]$, it was observed that the role of water was to increase the concentration of $\mathrm{Zn}^{2+}$ ions in the solution, since zinc acetate is more soluble in water than alcohol $[47,48]$. Thus, it seems reasonable to arrive at a similar conclusion for the $\mathrm{CuO}$ synthesis, that the role of water is to promote the forward reaction due to a higher concentration of $\mathrm{Cu}^{2+}$ ions in the solution. Fits of the XRD peaks to the Scherrer equation for the NCs synthesized with water gave a $\mathrm{CuONC}$ size of $(5.1 \pm 0.8) \mathrm{nm}$, which is consistent with the average NC size discerned from the TEM image.

Importantly, the $\mathrm{CuO} \mathrm{NCs}$ can be dispersed in a $2: 1$ solvent mixture of chloroform and methanol (see inset in Figure 1(a)). To understand the dispersion behavior, the NC surface chemistry and surface bound species were investigated using infrared spectroscopy. Figure 2 shows an FTIR spectrum of drop-casted $\mathrm{CuO}$ NCs. The peak at $1560 \mathrm{~cm}^{-1}$ is rather difficult to assign since both the water $\mathrm{H}-\mathrm{O}-\mathrm{H}$ scissoring vibration and the carboxylate anion asymmetrical stretching fall within this range [49], but both should be 


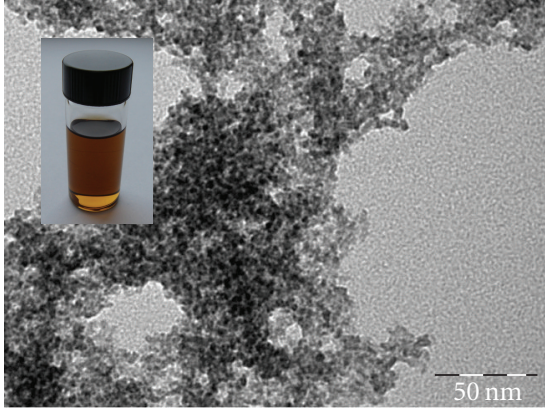

(a)

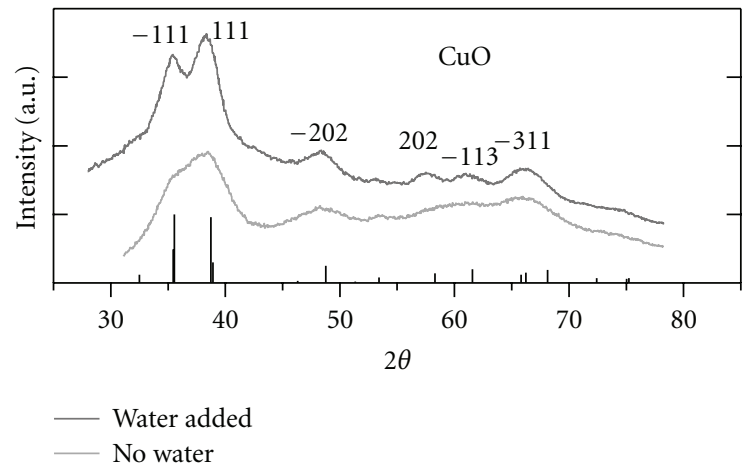

(b)

Figure 1: (a) TEM image of CuO NCs, (b) X-ray diffractograms of $\mathrm{CuO}$ NCs, with comparison between 2 syntheses: one with water added and the other without any water. The black lines represent literature values for $\mathrm{CuO}$ (JPCD\# 05-0661). Inset shows a dispersion of $\mathrm{CuO}$ NCs in a solvent mixture of methanol and chloroform.

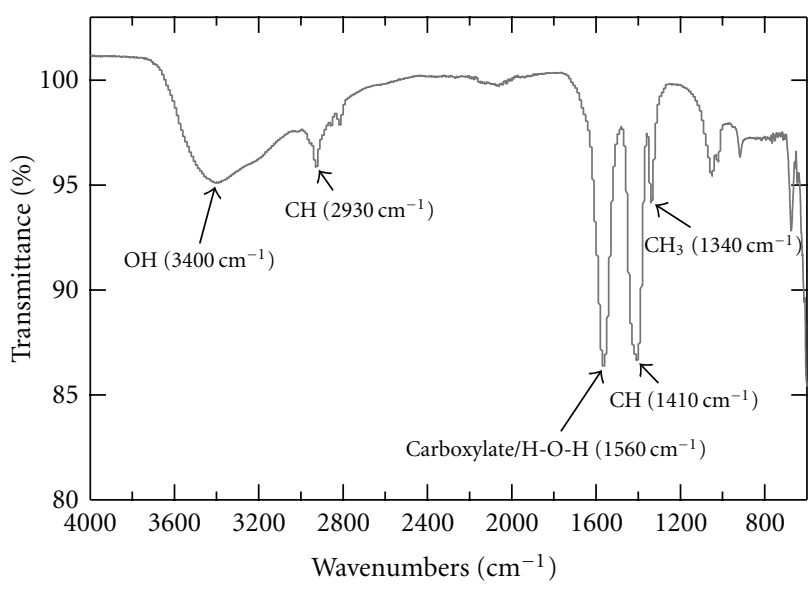

FIgURE 2: FTIR spectrum of CuO NCs.

represented since they are both present in the reaction. The data thus suggests that acetate (accounting for both the carboxylate and $\mathrm{CH}$ peaks), hydroxide, and water molecules from the synthesis are adsorbed onto the NC surfaces. The presence of both polar and organic groups explains why the $\mathrm{CuO}$ NCs can be readily dispersed in the chloroform and methanol mixture.
Figure 3(a) shows the absorption spectra of $\mathrm{CuO}(80 \mathrm{~nm})$ and PCBM $(120 \mathrm{~nm})$ films spin-casted from dispersions in their respective solvents. The $\mathrm{CuO}$ film absorption data was used to generate Tauc plots to determine the energy gap of the NCs (Figures 3(b) and 3(c)), which indicate a direct energy-gap at $3.07 \mathrm{eV}$ and an indirect energy-gap at $1.40 \mathrm{eV}$. The latter value is similar to the value for the indirect bulk band-gap reported in the literature [19]. While there have been reports of quantum confinement observed in $\mathrm{CuO}$ nanostructures $[33,35]$, the authors did not perform an indirect energy-gap fit to their data; hence it is difficult to make meaningful comparisons.

As a proof of concept of the potential applications of the $\mathrm{CuO}$ NCs, a bilayer solar cell comprising of $\mathrm{CuO}$ and a fullerene derivative, phenyl- $\mathrm{C}_{61}$-butyric acid methyl ester (PCBM), was fabricated. A single layer of $\mathrm{CuO}$ is unsuitable as the active layer, since the NC film contains cracks and pinholes and will result in a short-circuited device. This is similar to what has been reported about PbSe NC films, which require multiple sequential depositions of $\mathrm{NCs}$ and cross-linking to fill up the cracks [6]. PCBM is chosen since it is the acceptor of choice in solution-processable polymer solar cells [50], and its good film forming property allows it to cover up cracks in the $\mathrm{CuO}$ film. The literature value energy levels of the conduction and valence bands of $\mathrm{CuO}$ [19] and the lowest unoccupied molecular orbital (LUMO) and highest occupied molecular orbital (HOMO) of PCBM [51] are such that $\mathrm{CuO}$ and PCBM form a type II semiconductor heterojunction; hence they are suitable as a donor and acceptor pair. Figure 4(a) shows a schematic of the device stack with indium tin oxide (ITO) forming the anode and $\mathrm{CsF} / \mathrm{Al}$ as the cathode, as well as the literature values for the semiconductor energy levels $[19,51,52]$. Assignment of bulk $\mathrm{CuO}$ energy levels is supported by the small difference in NC optical band-gap relative to the literature (bulk) values [19].

Figure 4(b) shows the device current density voltage $(J-V)$ curves both in the dark and light (under AM $1.5100 \mathrm{~mW} \mathrm{~cm}^{-2}$ illumination) of a bi-layer cell with a $40 \mathrm{~nm}$ thick $\mathrm{CuO}$ layer. The device is characterized by a $V_{\text {OC }}$ of $0.44 \mathrm{~V}, J_{\text {SC }}$ of $0.24 \mathrm{~mA} \mathrm{~cm}^{-2}$, fill factor (FF) of 0.38 , and a power conversion efficiency (PCE) of $0.040 \%$. As a control, a PCBM-only cell (without $\mathrm{CuO}$ ) was fabricated and tested (also shown in Figure 4(b)). It shows a much lower $J_{\mathrm{SC}}$ of $0.03 \mathrm{~mA} \mathrm{~cm}^{-2}$ and PCE of $0.011 \%$, although it gave a higher $V_{\mathrm{OC}}$ of $0.78 \mathrm{~V}$ and slightly higher FF of 0.41 . Meanwhile, a bi-layer cell with a thicker $\mathrm{CuO}(\sim 70 \mathrm{~nm})$ layer is characterized by poorer $J_{\mathrm{SC}}\left(0.15 \mathrm{~mA} \mathrm{~cm}^{-2}\right), \mathrm{FF}(0.35)$, and PCE $(0.024 \%)$ compared to the cell with thinner $\mathrm{CuO}$ (refer to Table 1 for a summary of device results). These results lead to the conclusion that efficient charge collection is only taking place in the thin $\mathrm{CuO}$ layer near the interface, and additional $\mathrm{CuO}$ layer thickness does not contribute to the photocurrent while possibly adding to series resistance and recombination as indicated by the poorer FF. Improvements in the charge collection from $\mathrm{CuONC}$ absorber layers will therefore require better charge transport characteristics within the NC layer. One possible route to improving the charge collection is to use semiconductor nanowires (such 


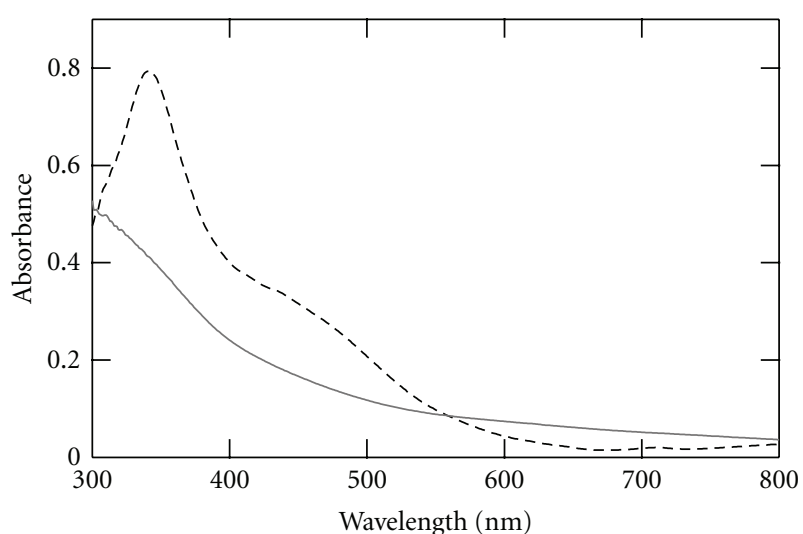

- $\mathrm{CuO}(80 \mathrm{~nm})$

... $\operatorname{PCBM}(120 \mathrm{~nm})$

(a)

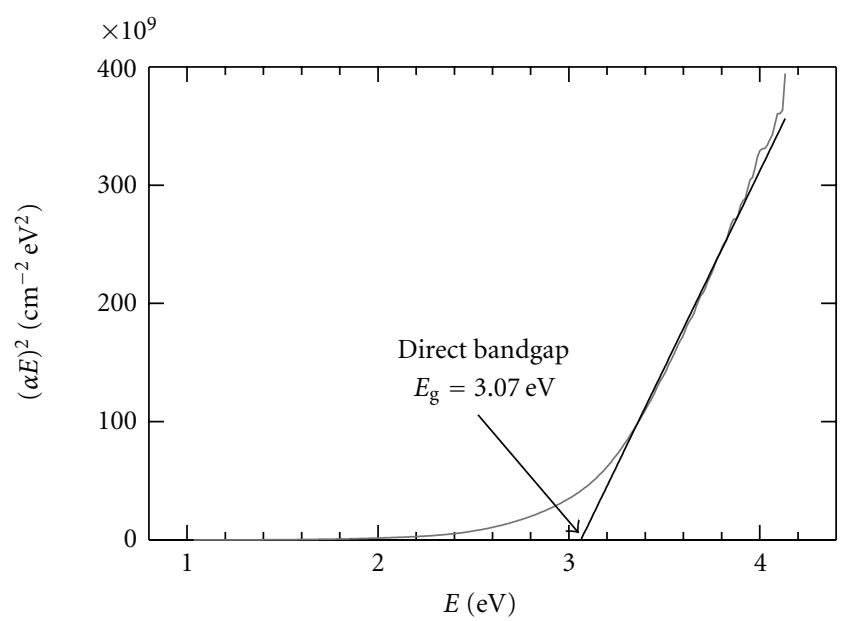

(b)

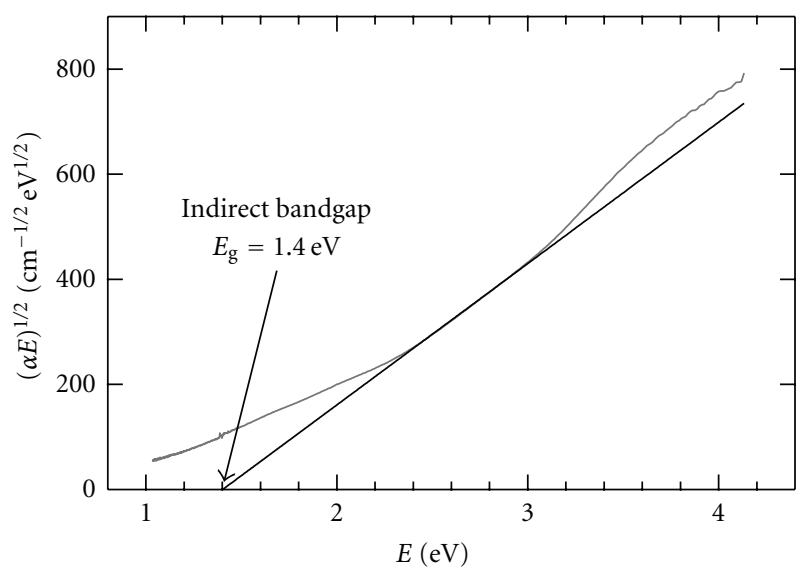

(c)

FIGURE 3: Optical properties of CuO NCs: (a) UV-Visible absorption spectra for spin-casted $\mathrm{CuO}$ and PCBM films (b) Tauc plot for the direct $\mathrm{CuO}$ band-gap fit (c) Indirect band-gap Tauc plot fit.

as n-type $\mathrm{ZnO}$ or $\mathrm{TiO}_{2}$ ) as the acceptor material, and the $\mathrm{CuO}$ NCs are then infiltrated into the gaps of the nanowires. Such device architectures have the advantage of separating

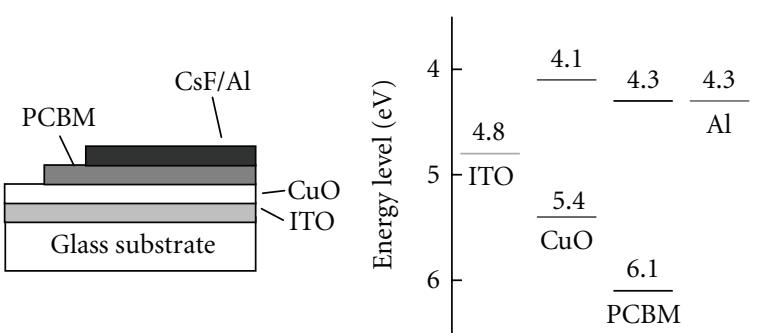

(a)

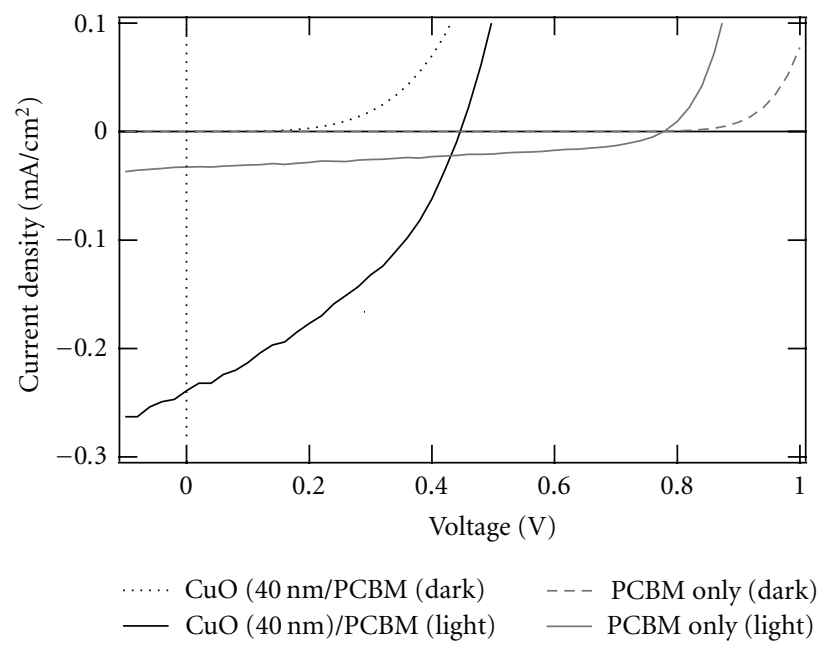

(b)

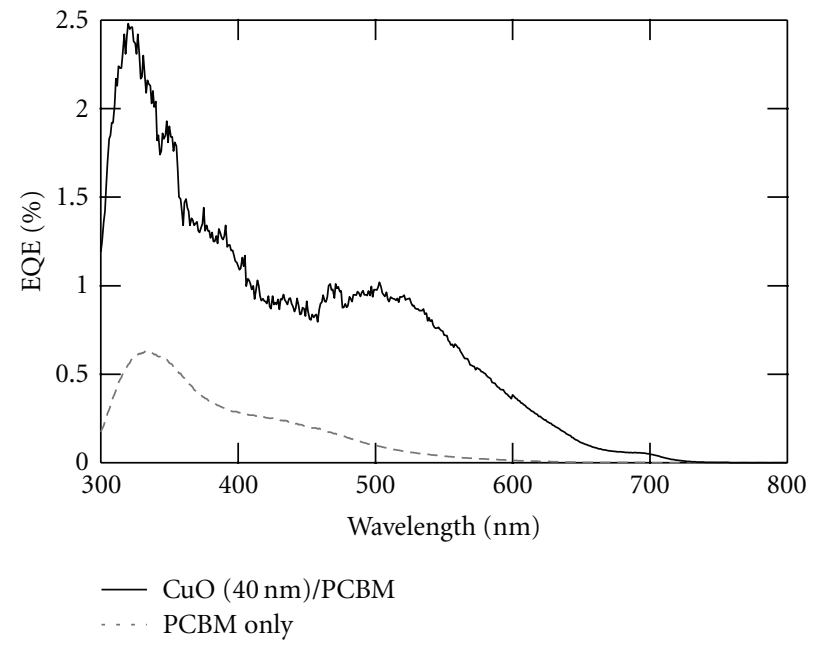

(c)

Figure 4: Performance of a CuO/PCBM bilayer solar cell: (a) Device stack and energy level diagram, (b) $J-V$ curves in the dark and light (AM $1.5100 \mathrm{~mW} \mathrm{~cm}^{-2}$ ), (c) EQE comparison between the bilayer cell and a PCBM only cell.

the light absorption and charge collection pathways so that both processes can be efficient [8].

External quantum efficiency (EQE) spectra of the devices are shown in Figure 4(c). The bi-layer cell shows a superior EQE to the PCBM-only cell, and the improved EQE at higher wavelengths beyond $550 \mathrm{~nm}$ can be attributed to the contribution from the $\mathrm{CuO}$ by taking into account the 
TABLE 1: Summary of solar cell device results.

\begin{tabular}{lcccc}
\hline Active layer & $V_{\mathrm{OC}}(\mathrm{V})$ & $\begin{array}{c}J_{\mathrm{SC}} \\
\left(\mathrm{mA} / \mathrm{cm}^{2}\right)\end{array}$ & Fill Factor & $\begin{array}{c}\text { PCE } \\
(\%)\end{array}$ \\
\hline $\mathrm{CuO}(40 \mathrm{~nm}) / \mathrm{PCBM}$ & 0.44 & 0.24 & 0.38 & 0.040 \\
$\mathrm{CuO}(70 \mathrm{~nm}) / \mathrm{PCBM}$ & 0.46 & 0.15 & 0.35 & 0.024 \\
$\mathrm{PCBM}$ only & 0.78 & 0.03 & 0.41 & 0.011 \\
\hline
\end{tabular}

absorption spectra of both materials (Figure 3(a)). Since $J_{S C}$ is the integration of the EQE across the solar spectrum, the higher $J_{\mathrm{SC}}$ observed in the bi-layer cell is clearly due to its superior EQE.

\section{Conclusions}

A synthesis of $\mathrm{CuONCs}$ by a facile alcohothermal route has been presented. The CuO NCs are soluble in a chloroform/methanol mixture, thus enabling the processing of these materials by solution. A bi-layer $\mathrm{CuO}$ and PCBM solar cell achieved a power conversion efficiency of $0.04 \%$, which is 4 times higher than the control PCBM-only cell, indicating the potential of these $\mathrm{CuONCs}$ for lightharvesting applications.

\section{Acknowledgments}

This work was funded by the KAUST-Cornell Center for Energy and Sustainability. The authors thank Dr. Jacek Jasieniak (CSIRO, Australia) for inspiration for the copper oxide synthesis and helpful comments on the paper, William Baumgardner and John Grazul for assistance with TEM imaging, and Dr. Maura Weathers for assistance with XRD. Device fabrication and testing was performed partly in the laboratory of Professor George Malliaras, while nanocrystal characterization was done using equipment in the Cornell Center for Materials Research (CCMR), Cornell Center for Nanoscale Systems (CNS), Cornell Nanoscale Science \& Technology Facility (CNF), and the KAUST-Cornell Center for Energy and Sustainability. Y. F. Lim acknowledges a research fellowship from A*STAR, Singapore. J. J. Choi acknowledges support from NSF IGERT fellowship.

\section{References}

[1] C. J. Brabec and J. R. Durrant, "Solution-processed organic solar cells," MRS Bulletin, vol. 33, no. 7, pp. 670-675, 2008.

[2] J. Tang and E. H. Sargent, "Infrared colloidal quantum dots for photovoltaics: fundamentals and recent progress," Advanced Materials, vol. 23, no. 1, pp. 12-29, 2011.

[3] W. U. Huynh, J. J. Dittmer, and A. P. Alivisatos, "Hybrid nanorod-polymer solar cells," Science, vol. 295, no. 5564, pp. 2425-2427, 2002.

[4] I. Gur, N. A. Fromer, M. L. Geier, and A. P. Alivisatos, "Materials science: air-stable all-inorganic nanocrystal solar cells processed from solution," Science, vol. 310, no. 5747, pp. 462-465, 2005.
[5] Q. Guo, S. J. Kim, M. Kar et al., "Development of CulnSe nanocrystal and nanoring inks for low-cost solar cells," Nano Letters, vol. 8, no. 9, pp. 2982-2987, 2008.

[6] J. M. Luther, M. Law, M. C. Beard et al., "Schottky solar cells based on colloidal nanocrystal films," Nano Letters, vol. 8, no. 10, pp. 3488-3492, 2008.

[7] K. S. Leschkies, T. J. Beatty, M. S. Kang, D. J. Norris, and E. S. Aydil, "Solar cells based on junctions between colloidal Pbse nanocrystals and thin ZnO films," ACS Nano, vol. 3, no. 11, pp. 3638-3648, 2009.

[8] K. S. Leschkies, A. G. Jacobs, D. J. Norris, and E. S. Aydil, "Nanowire-quantum-dot solar cells and the influence of nanowire length on the charge collection efficiency," Applied Physics Letters, vol. 95, no. 19, Article ID 193103, 2009.

[9] J. J. Choi, Y. F. Lim, M. B. Santiago-Berrios et al., "PbSe Nanocrystal Excitonic Solar Cells," Nano Letters, vol. 9, no. 11, pp. 3749-3755, 2009.

[10] C. Y. Kuo, M. S. Su, Y. C. Hsu, H. N. Lin, and K. H. Wei, "An organic hole transport layer enhances the performance of colloidal PbSe quantum dot photovoltaic devices," Advanced Functional Materials, vol. 20, no. 20, pp. 3555-3560, 2010.

[11] J. M. Luther, J. Gao, M. T. Lloyd, O. E. Semonin, M. C. Beard, and A. J. Nozik, "Stability assessment on a $3 \%$ bilayer $\mathrm{PbS} / \mathrm{ZnO}$ quantum dot heterojunction solar cell," Advanced Materials, vol. 22, no. 33, pp. 3704-3707, 2010.

[12] J. J. Choi, W. Wenger, R. Hoffman et al., "Solution-processed nanocrystal quantum dot tandem solar cells," Advanced Materials, vol. 23, no. 28, pp. 3144-3148, 2011.

[13] S. W. Tsang, H. Fu, J. Ouyang et al., "Self-organized phase segregation between inorganic nanocrystals and $\mathrm{PC}_{61} \mathrm{BM}$ for hybrid high-efficiency bulk heterojunction photovoltaic cells," Applied Physics Letters, vol. 96, no. 24, Article ID 243104, 2010.

[14] R. Debnath, J. Tang, D. A. Barkhouse et al., "Ambientprocessed colloidal quantum dot solar cells via individual pre-encapsulation of nanoparticles," Journal of the American Chemical Society, vol. 132, no. 17, pp. 5952-5953, 2010.

[15] A. G. Pattantyus-Abraham, I. J. Kramer, A. R. Barkhouse et al., "Depleted-heterojunction colloidal quantum dot solar cells," ACS Nano, vol. 4, no. 6, pp. 3374-3380, 2010.

[16] P. H. Stauffer and J. W. Hendley II, "Rare Earth ElementsCritical Resources for High Technology," USGS Fact Sheet 087-02, 2011, http://pubs.usgs.gov/fs/2002/fs087-02 .

[17] C. Wadia, A. P. Alivisatos, and D. M. Kammen, "Materials availability expands the opportunity for large-scale photovoltaics deployment," Environmental Science and Technology, vol. 43, no. 6, pp. 2072-2077, 2009.

[18] Y. Wu, C. Wadia, W. Ma, B. Sadtler, and A. P. Alivisatos, "Synthesis and photovoltaic application of copper(1) sulfide nanocrystals," Nano Letters, vol. 8, no. 8, pp. 2551-2555, 2008.

[19] F. P. Koffyberg and F. A. Benko, "A photoelectrochemical determination of the position of the conduction and valence band edges of p-type CuO," Journal of Applied Physics, vol. 53, no. 2, pp. 1173-1177, 1982.

[20] G. Nagasubramanian, A. S. Gioda, and A. J. Bard, "Semiconductor electrodes - 37. Photoelectrochemical behavior of p-type $\mathrm{Cu} / \mathrm{sub} 2 / \mathrm{O}$ in acetonitrile solutions," Journal of the Electrochemical Society, vol. 128, no. 10, pp. 2158-2164, 1981.

[21] W. Shockley and H. J. Queisser, "Detailed balance limit of efficiency of $p-n$ junction solar cells," Journal of Applied Physics, vol. 32, no. 3, pp. 510-519, 1961.

[22] B. P. Rai, " $\mathrm{Cu}_{2} \mathrm{O}$ solar cells: a review," Solar Cells, vol. 25, no. 3, pp. 265-272, 1988. 
[23] T. Minami, H. Tanaka, T. Shimakawa, T. Miyata, and H. Sato, "High-efficiency oxide heterojunction solar cells using $\mathrm{Cu}_{2} \mathrm{O}$ sheets," Japanese Journal of Applied Physics, vol. 43, no. 7A, pp. L917-L919, 2004.

[24] T. Minami, T. Miyata, K. Ihara, Y. Minamino, and S. Tsukada, "Effect of $\mathrm{ZnO}$ film deposition methods on the photovoltaic properties of $\mathrm{ZnO}-\mathrm{Cu}_{2} \mathrm{O}$ heterojunction devices," Thin Solid Films, vol. 494, no. 1-2, pp. 47-52, 2006.

[25] A. Mittiga, E. Salza, F. Sarto, M. Tucci, and R. Vasanthi, "Heterojunction solar cell with $2 \%$ efficiency based on a $\mathrm{Cu}_{2} \mathrm{O}$ substrate," Applied Physics Letters, vol. 88, no. 16, Article ID 163502, 2006.

[26] K. H. Yoon, W. J. Choi, and D. H. Kang, "Photoelectrochemical properties of copper oxide thin films coated on an n-Si substrate," Thin Solid Films, vol. 372, no. 1, pp. 250-256, 2000.

[27] Y. S. Chaudhary, A. Agrawal, R. Shrivastav, V. R. Satsangi, and S. Dass, "A study on the photoelectrochemical properties of copper oxide thin films," International Journal of Hydrogen Energy, vol. 29, no. 2, pp. 131-134, 2004.

[28] S. Anandan, X. Wen, and S. Yang, "Room temperature growth of $\mathrm{CuO}$ nanorod arrays on copper and their application as a cathode in dye-sensitized solar cells," Materials Chemistry and Physics, vol. 93, no. 1, pp. 35-40, 2005.

[29] C. H. Kuo and M. H. Huang, "Morphologically controlled synthesis of $\mathrm{Cu}_{2} \mathrm{O}$ nanocrystals and their properties," Nano Today, vol. 5, no. 2, pp. 106-116, 2010.

[30] M. Cao, C. Hu, Y. Wang, Y. Guo, C. Guo, and E. Wang, "A controllable synthetic route to $\mathrm{Cu}, \mathrm{Cu}_{2} \mathrm{O}$, and $\mathrm{CuO}$ nanotubes and nanorods," Chemical Communications, vol. 9, no. 15, pp. 1884-1885, 2003.

[31] W. Wang, Z. Liu, Y. Liu, C. Xu, C. Zheng, and G. Wang, "A simple wet-chemical synthesis and characterization of $\mathrm{CuO}$ nanorods," Applied Physics A: Materials Science and Processing, vol. 76, no. 3, pp. 417-420, 2003.

[32] Y. Chang and H. C. Zeng, "Controlled synthesis and selfassembly of single-crystalline $\mathrm{CuO}$ nanorods and nanoribbons," Crystal Growth and Design, vol. 4, no. 2, pp. 397-402, 2004.

[33] J. Zhu, H. Chen, H. Liu, X. Yang, L. Lu, and X. Wang, "Needleshaped nanocrystalline $\mathrm{CuO}$ prepared by liquid hydrolysis of $\mathrm{Cu}(\mathrm{OAc})_{2}$," Materials Science and Engineering A, vol. 384, no. 1-2, pp. 172-176, 2004.

[34] Y. Yu, F. P. Du, J. C. Yu, Y. Y. Zhuang, and P. K. Wong, “Onedimensional shape-controlled preparation of porous $\mathrm{Cu}_{2} \mathrm{O}$ nano-whiskers by using CTAB as a template," Journal of Solid State Chemistry, vol. 177, no. 12, pp. 4640-4647, 2004.

[35] H. Fan, L. Yang, W. Hua et al., "Controlled synthesis of monodispersed $\mathrm{CuO}$ nanocrystals," Nanotechnology, vol. 15, no. 1, pp. 37-42, 2004.

[36] C. Lu, L. Qi, J. Yang et al., "One-pot synthesis of octahedral $\mathrm{Cu}_{2} \mathrm{O}$ nanocages via a catalytic solution route," Advanced Materials, vol. 17, no. 21, pp. 2562-2567, 2005.

[37] P. He, X. Shen, and H. Gao, "Size-controlled preparation of $\mathrm{Cu}_{2} \mathrm{O}$ octahedron nanocrystals and studies on their optical absorption," Journal of Colloid and Interface Science, vol. 284, no. 2, pp. 510-515, 2005.

[38] J. Zhang, J. Liu, Q. Peng, X. Wang, and Y. Li, "Nearly monodisperse $\mathrm{Cu}_{2} \mathrm{O}$ and $\mathrm{CuO}$ nanospheres: Preparation and applications for sensitive gas sensors," Chemistry of Materials, vol. 18 , no. 4 , pp. 867-871, 2006.

[39] J. Y. Ho and M. H. Huang, "Synthesis of submicrometersized $\mathrm{Cu}_{2} \mathrm{O}$ crystals with morphological evolution from cubic to hexapod structures and their comparative photocatalytic activity," Journal of Physical Chemistry C, vol. 113, no. 32, pp. 14159-14164, 2009.

[40] K. X. Yao, X. M. Yin, T. H. Wang, and H. C. Zeng, "Synthesis, self-assembly, disassembly, and reassembly of two types of $\mathrm{Cu}_{2} \mathrm{O}$ nanocrystals unifaceted with 001 or 110 planes," Journal of the American Chemical Society, vol. 132, no. 17, pp. 61316144, 2010.

[41] M. Yin, C. K. Wu, Y. Lou et al., "Copper oxide nanocrystals," Journal of the American Chemical Society, vol. 127, no. 26, pp. 9506-9511, 2005.

[42] T. Kida, T. Oka, M. Nagano, Y. Ishiwata, and X. G. Zheng, "Synthesis and application of stable copper oxide nanoparticle suspensions for nanoparticulate film fabrication," Journal of the American Ceramic Society, vol. 90, no. 1, pp. 107-110, 2007.

[43] B. D. Yuhas and P. Yang, "Nanowire-based all-oxide solar cells," Journal of the American Chemical Society, vol. 131, no. 10, pp. 3756-3761, 2009.

[44] L. L. Hung, C. K. Tsung, W. Huang, and P. Yang, "Roomtemperature formation of hollow $\mathrm{Cu}_{2} \mathrm{O}$ nanoparticles," Advanced Materials, vol. 22, no. 17, pp. 1910-1914, 2010.

[45] W. J. E. Beek, M. M. Wienk, M. Kemerink, X. Yang, and R. A. J. Janssen, "Hybrid zinc oxide conjugated polymer bulk heterojunction solar cells," Journal of Physical Chemistry B, vol. 109, no. 19, pp. 9505-9516, 2005.

[46] C. B. Murray, D. J. Norris, and M. G. Bawendi, "Synthesis and characterization of nearly monodisperse $\mathrm{CdE}$ ( $\mathrm{E}=$ sulfur, selenium, tellurium) semiconductor nanocrystallites," Journal of the American Chemical Society, vol. 115, no. 19, pp. 87068715, 1993.

[47] E. A. Meulenkamp, "Synthesis and growth of $\mathrm{ZnO}$ nanoparticles," Journal of Physical Chemistry B, vol. 102, no. 29, pp. 5566-5572, 1998.

[48] M. S. Tokumoto, S. H. Pulcinelli, C. V. Santilli, and V. Briois, "Catalysis and temperature dependence on the formation of $\mathrm{ZnO}$ nanoparticles and of zinc acetate derivatives prepared by the sol-gel route," Journal of Physical Chemistry B, vol. 107, no. 2, pp. 568-574, 2003.

[49] R. M. Silverstein and F. X. Webster, Spectrometric Identification of Organic Compounds, John Wiley \& Sons, New York, NY, USA, 1998.

[50] C. J. Brabec, S. Gowrisanker, J. J. M. Halls, D. Laird, S. Jia, and S. P. Williams, "Polymer-fullerene bulk-heterojunction solar cells," Advanced Materials, vol. 22, no. 34, pp. 3839-3856, 2010.

[51] Y. K. Jin, K. Lee, N. E. Coates et al., "Efficient tandem polymer solar cells fabricated by all-solution processing," Science, vol. 317, no. 5835, pp. 222-225, 2007.

[52] K. Sugiyama, H. Ishii, Y. Ouchi, and K. Seki, "Dependence of indium-tin-oxide work function on surface cleaning method as studied by ultraviolet and x-ray photoemission spectroscopies," Journal of Applied Physics, vol. 87, no. 1, pp. 295-298, 2000 . 

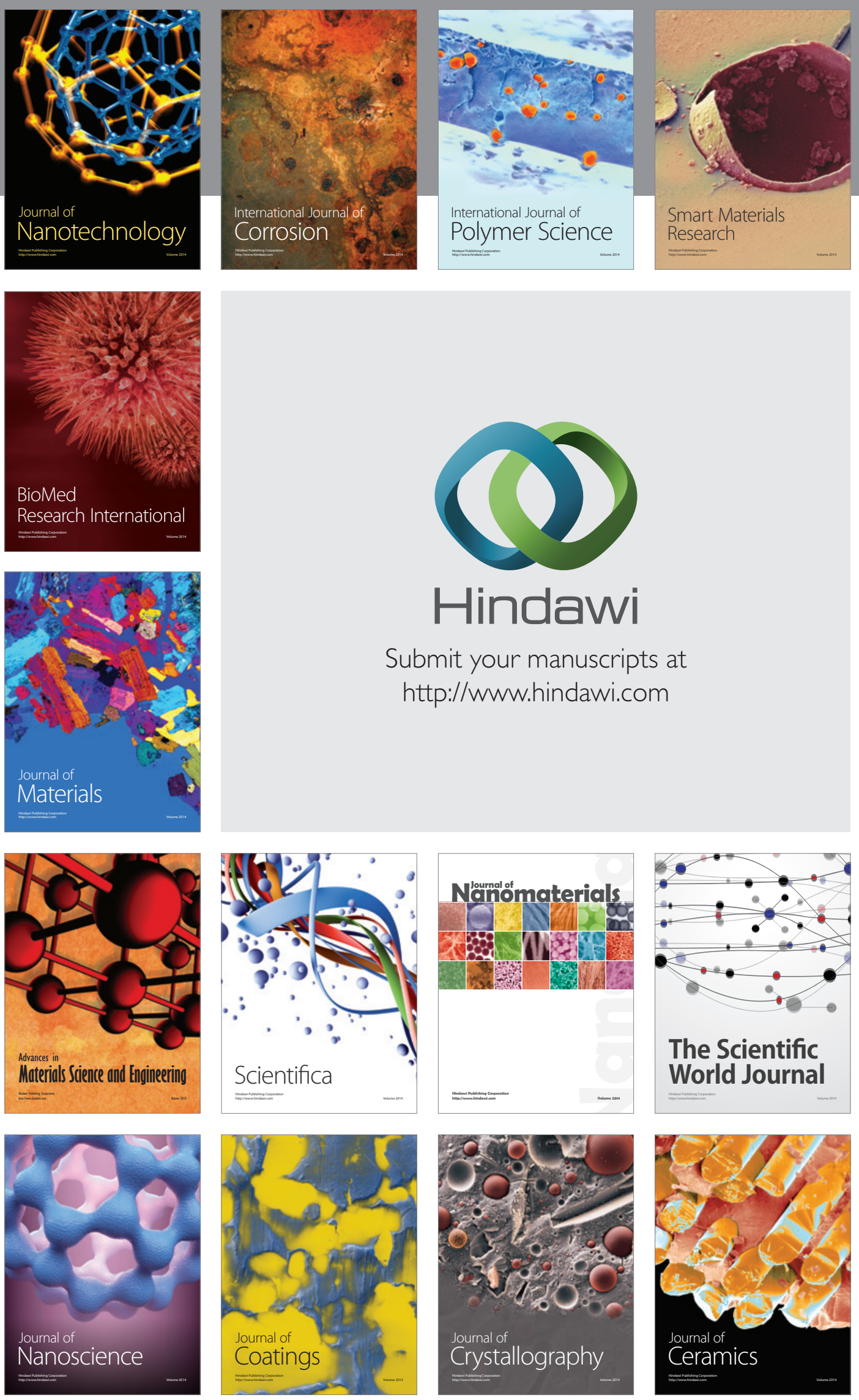

The Scientific World Journal

Submit your manuscripts at

http://www.hindawi.com

\section{World Journal}

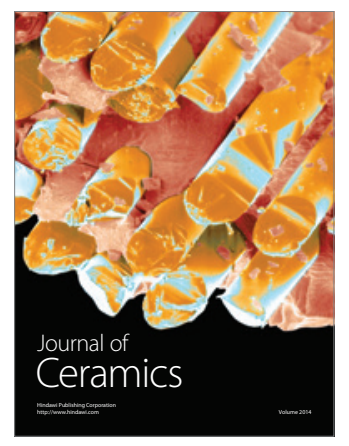

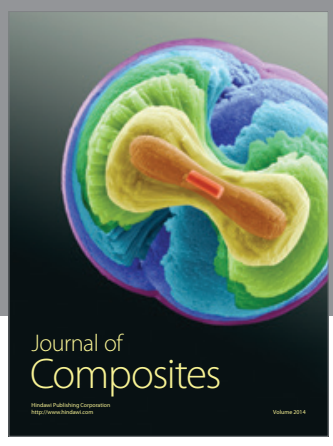
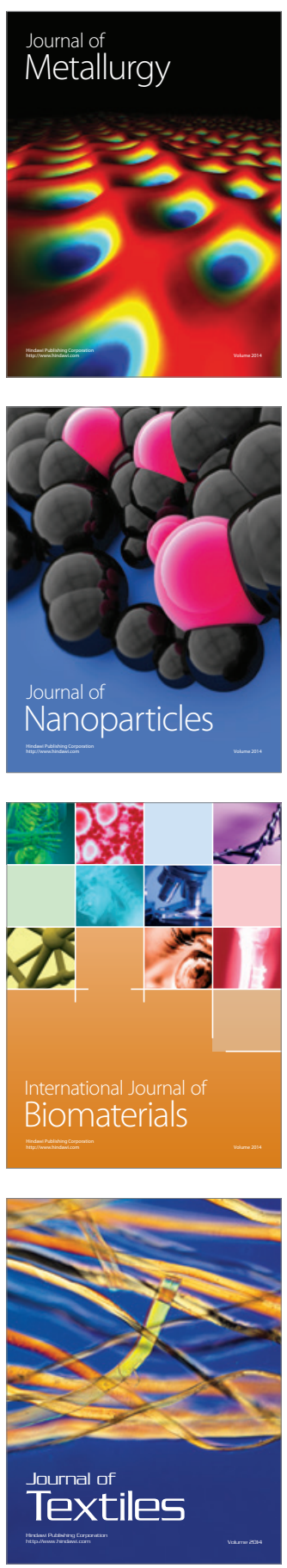